\title{
Corrosion inhibition of mild steel by N, N'-(5,5- dimethylcyclohexane-1,3- diylidene)dianiline in acid media: Gravimetric and electrochemical evaluations
}

\author{
K. Ragia , Joby Thomas Kakkassery ${ }^{a *}$, Vinod P. Raphael ${ }^{b}$, Binsi M. Paulsona and Reeja \\ Johnson ${ }^{\text {a }}$
}

${ }^{a}$ Department of Chemistry, St. Thomas' College Autonomous (University of Calicut), Thrissur, India-680001 ${ }^{b}$ Department of Chemistry, Govt. Engineering College, Thrissur, India-680009

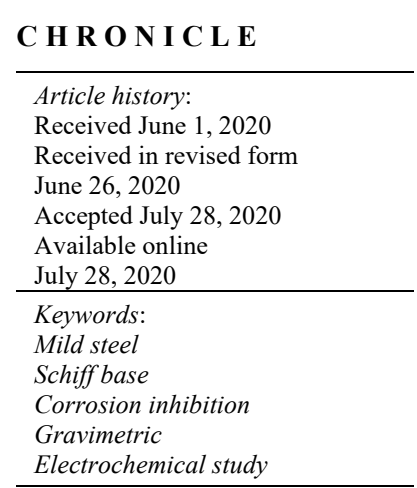

\begin{abstract}
A B S T R A C T
The corrosion inhibition efficiency of the Schiff base N,N'-(5,5-dimethylcyclohexane-1,3diylidene)dianiline (DmChDa) on mild steel in $1 \mathrm{M} \mathrm{HCl}$ and $0.5 \mathrm{M} \mathrm{H}_{2} \mathrm{SO}_{4}$ was evaluated using gravimetric, electrochemical impedance spectroscopy, potentiodynamic polarization and electrochemical noise measurement. Experimental results established that DmChDa possess relatively high corrosion inhibition capacity. Langmuir and El-Awady adsorption isotherms were obeyed by the Schiff base in $1 \mathrm{M} \mathrm{HCl}$ and $0.5 \mathrm{M} \mathrm{H}_{2} \mathrm{SO}_{4}$ respectively. SEM analysis showed that DmChDa was adsorbed on the steel surface during corrosion inhibition. The variation of metal dissolution with temperature was also examined using gravimetric study.
\end{abstract}

(C) 2021 Growing Science Ltd. All rights reserved.

\section{Introduction}

Mild steel plays a significant role in our day-to-day life on account of their excellent mechanical property and low price..$^{1-5}$ They are used extensively as building materials, for storage tanks, reactors, boilers, oil and gas transport pipelines and heat exchange processes. Acid solutions are used in industries for various cleaning purposes such as acid-descaling, acid-cleaning, acid-pickling, oil-well acidizing etc. During these cleaning processes, mild steel is attacked severely by the acid solution and gets corroded. $^{6-9}$ The best method for reducing the destruction of metal during pickling is the use of inhibitors. Schiff bases which are formed by the condensation of amino acid and aldehydes/ketones has wide applications in various fields such as pharmaceuticals, catalysis, antimicrobial activity, coordination chemistry, agricultural and material science etc. They are also being utilized as a potent corrosion inhibitor for a number of reasons such as the presence of azomethine $(-\mathrm{CH}=\mathrm{N}-)$ group, oxygen, nitrogen and sulphur atoms, unsaturation sites and aromatic rings. ${ }^{10-12}$ The substitution of groups like $\mathrm{OH}$ on the benzene ring present in the ligand molecule will enhance the corrosion inhibition capacity as per our previous work. ${ }^{4}$ The important aspect of the Schiff base molecule that decides

* Corresponding author. Tel.: +91 9847177695

E-mail address: drjobythomask@gmail.com (J. T. Kakkassery)

(C) 2021 Growing Science Ltd. All rights reserved.

doi: $10.5267 /$ j.ccl.2020.8.001 
adsorption of it on the surface of the metal is a lone pair of electrons on hetero atoms. The main advantage of Schiff bases is that they can be synthesized easily from cost-effective raw material. In the present study, the corrosion inhibition nature of the Schiff base DmChDa on mild steel in $1 \mathrm{M} \mathrm{HCl}$ and $0.5 \mathrm{M} \mathrm{H} \mathrm{H}_{2} \mathrm{SO}_{4}$ were analyzed experimentally using weight loss, electrochemical impedance spectroscopy, potentiodynamic polarization and electrochemical noise measurement.

\section{Results and discussion}

\subsection{Weight loss studies}

\subsubsection{Impact of inhibitor concentration}

The weight loss of the MS specimen at $24 \mathrm{~h}$ interval in acid media in the absence and presence of various inhibitors at different concentrations were determined. The corrosion rate and inhibition efficiency were calculated, which is depicted in Table 1. The rate of corrosion of MS decreased in the presence of DmChDa. DmChDa has higher inhibition efficiency in $1 \mathrm{M} \mathrm{HCl}$ than $0.5 \mathrm{M} \mathrm{H}_{2} \mathrm{SO}_{4}$ at all concentrations. The maximal values of corrosion inhibition efficiency on the MS surface by $1 \mathrm{mM}$ inhibitor concentration in $1 \mathrm{M} \mathrm{HCl}$ and $0.5 \mathrm{M} \mathrm{H}_{2} \mathrm{SO}_{4}$ were found to be $92.63 \%$ and $87.52 \%$ respectively.

Table 1. The rate of corrosion of MS and corrosion inhibition efficiency of DmChDa in acid media at $28^{\circ} \mathrm{C}$ for $24 \mathrm{~h}$

\begin{tabular}{|c|c|c|c|c|}
\hline \multirow[b]{2}{*}{$\begin{array}{l}\text { Conc. } \\
(\mathrm{mM})\end{array}$} & \multicolumn{2}{|c|}{$1 \mathrm{M} \mathrm{HCl}$} & \multicolumn{2}{|c|}{$0.5 \mathrm{M} \mathrm{H}_{2} \mathrm{SO}_{4}$} \\
\hline & $\begin{array}{l}\text { Corrosion rate }(v) \\
\quad\left(\mathrm{mmy}^{-1}\right)\end{array}$ & $\begin{array}{c}\text { \%inhibition } \\
\text { efficiency } \\
\left(\prod_{\mathrm{w}} \%\right)\end{array}$ & $\begin{array}{l}\text { Corrosion rate }(v) \\
\left(\mathrm{mmy}^{-1}\right)\end{array}$ & $\begin{array}{l}\text { \%inhibition } \\
\text { efficiency } \\
\left(\Pi_{\mathrm{w}} \%\right)\end{array}$ \\
\hline 0.0 & 7.30 & - & 35.20 & - \\
\hline 0.2 & 1.41 & 80.67 & 24.16 & 31.36 \\
\hline 0.4 & 1.28 & 82.39 & 10.33 & 70.62 \\
\hline 0.6 & 1.01 & 86.07 & 6.81 & 80.64 \\
\hline 0.8 & 0.87 & 88.04 & 4.40 & 87.50 \\
\hline 1.0 & 0.53 & 92.63 & 4.39 & 87.52 \\
\hline
\end{tabular}

\subsubsection{Comparison between $\eta_{w} \%$ of DmChDa and its parent compounds}

In order to correlate the corrosion inhibition efficiency of Schiff base DmChDa with parent compounds 5-5-dimethyl-1,3-cyclohexanedione (Dm) and aniline (An), weight loss measurements of mild steel specimens were conducted in $1 \mathrm{M} \mathrm{HCl}$ and $0.5 \mathrm{M} \mathrm{H}_{2} \mathrm{SO}_{4}$ and the efficiencies are given in Table 2. The corrosion inhibition efficiency of $\mathrm{DmChDa}$ was remarkably higher than the parent compounds. It is due to the involvement of $\mathrm{C}=\mathrm{N}$ - group present in the inhibitor molecule during adsorption phenomena. ${ }^{13}$

Table 2. The corrosion inhibition efficiency of parent ketone (Dm) and amine (An) of DmChDa on MS in acid media

\begin{tabular}{ccccc}
\hline & \multicolumn{4}{c}{ \% inhibition efficiency $\left(\eta_{\mathrm{w}} \%\right)$} \\
\cline { 2 - 5 } Conc & \multicolumn{2}{c}{$1 \mathrm{M} \mathrm{HCl}$} & \multicolumn{2}{c}{$0.5 \mathrm{M} \mathrm{H}_{2} \mathrm{SO}_{4}$} \\
\cline { 2 - 5 }$(\mathrm{mM})$ & $\mathrm{Dm}$ & $\mathrm{An}$ & $\mathrm{Dm}$ & $\mathrm{An}$ \\
\hline 0.2 & -85.40 & -70.19 & 29.50 & 28.26 \\
0.6 & -70.67 & -8.46 & 38.68 & 29.70 \\
1 & -42.56 & 25.70 & 56.23 & 43.04 \\
\hline
\end{tabular}

\subsubsection{Determination of adsorption isotherm}

The mechanism of the inhibition of corrosion of MS can be elucidated with the help of adsorption isotherms. ${ }^{14}$ Langmuir, Temkin, El-Awady, Florry-huggin, Freundlich and Frumkin adsorption 
isotherms were considered, and the best suited isotherm was determined by calculating the correlation coefficient $\left(\mathrm{R}^{2}\right) .{ }^{15-16}$ The isotherms corresponding to $\mathrm{DmChDa}$ in $1 \mathrm{M} \mathrm{HCl}$ and $0.5 \mathrm{M} \mathrm{H}_{2} \mathrm{SO}_{4}$ medium were Langmuir and El-Awady adsorption isotherm respectively. These isotherms can be denoted as

$$
\begin{array}{ll}
\text { Langmuir isothem } & \frac{\mathrm{C}}{\theta}=\frac{1}{\mathrm{~K}}+\mathrm{C} \\
\text { El-awady isothem } & \log \frac{\theta}{(1-\theta)}=\log \mathrm{K}+\mathrm{y} \log \mathrm{C}
\end{array}
$$

where $\mathrm{C}, \theta$ and $\mathrm{K}_{\mathrm{ads}}$ denotes inhibitor concentration, fractional surface coverage and adsorption equilibrium constant respectively. The adsorption equilibrium constant correlates with standard free energy of adsorption $\Delta \mathrm{G}_{\text {ads }}$ as shown below ${ }^{17-18}$

$$
\Delta \mathrm{G}_{\mathrm{ads}}^{0}=-\mathrm{RT} \ln (55.5 \mathrm{Kads})
$$

where 55.5 is the molar concentration of water, $\mathrm{T}$ and $\mathrm{R}$ represent temperature in Kelvin and universal gas constant respectively. The $\Delta \mathrm{G}^{0}$ ads value upto $-20 \mathrm{kJmol}^{-1}$ indicates that the interaction of charged molecule and charged metal surface is electrostatic in nature (physisorption) while the value more negative than $-40 \mathrm{kJmol}^{-1}$ indicates the presence of co-ordinate type bond between inhibitor molecules and metal surface (chemisorption) ${ }^{19}$. The observed $\Delta \mathrm{G}^{0}$ ads values of DmChDa were -34.40 and -45.84 $\mathrm{kJmol}^{-1}$ respectively in $1 \mathrm{M} \mathrm{HCl}$ and $0.5 \mathrm{M} \mathrm{H}_{2} \mathrm{SO}_{4}$, indicating that the adsorption behaviour involves both chemical and electrostatic interaction in $1 \mathrm{M} \mathrm{HCl}$, whereas in $0.5 \mathrm{M} \mathrm{H}_{2} \mathrm{SO}_{4}$ the adsorption behaviour is mainly by chemical interaction. The isotherms of $\mathrm{DmChDa}$ on $\mathrm{MS}$ specimen in $1 \mathrm{M} \mathrm{HCl}$ and $0.5 \mathrm{M} \mathrm{H}_{2} \mathrm{SO}_{4}$ at $28^{\circ} \mathrm{C}$ is shown in Fig. 1. The mechanism of the interaction is shown in Fig. 2.
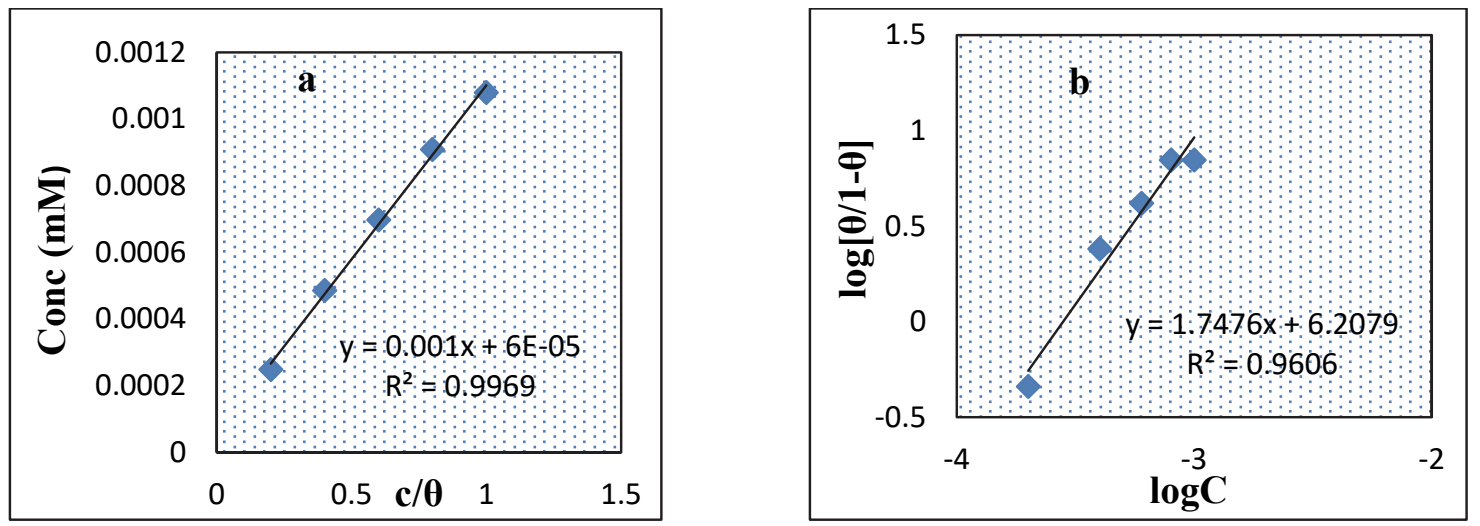

Fig. 1. (a) Langmuir adsorption isotherm of $\mathrm{DmChDa}$ on $\mathrm{MS}$ in $1 \mathrm{M} \mathrm{HCl}$ at $28^{\circ} \mathrm{C}$. (b) El-Awady adsorption isotherm of $\mathrm{DmChDa}$ on $\mathrm{MS}$ in $0.5 \mathrm{M} \mathrm{H}_{2} \mathrm{SO}_{4}$ at $28^{0} \mathrm{C}$

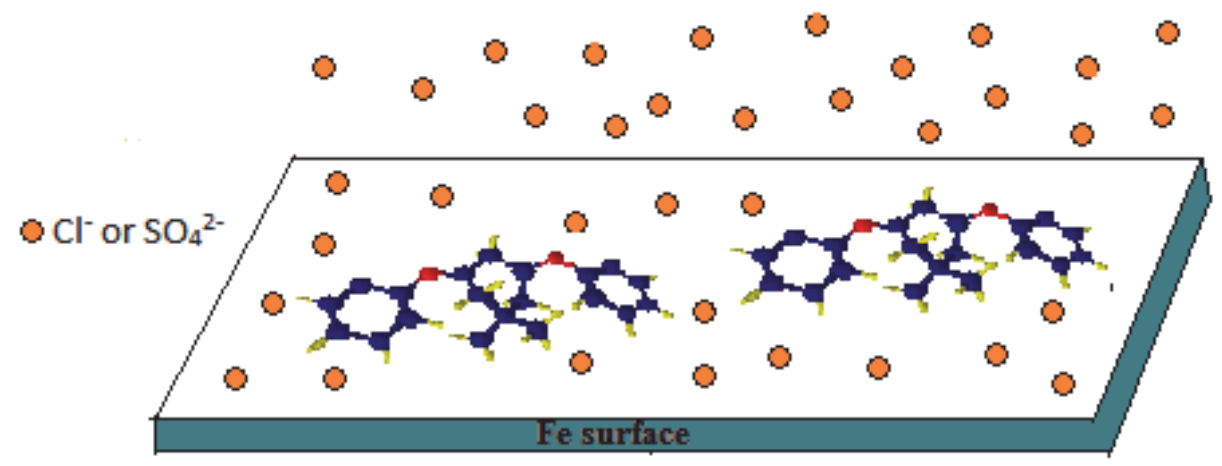

Fig. 2. Interaction of $\mathrm{DmChDa}$ on mild steel in acid media 


\subsubsection{Impact of temperature}

The impact of temperature on the rate of corrosion was investigated using weight loss studies in the temperature range $30-60^{\circ} \mathrm{C}$. The activation energy of metal dissolution was calculated using an Arrhenius type equation given below ${ }^{20-21}$

$$
\mathrm{K}=\operatorname{Aexp}\left(-\mathrm{E}_{\mathrm{a}} / \mathrm{RT}\right) \text {, }
$$

where $\mathrm{A}, \mathrm{K}, \mathrm{R}, \mathrm{T}$ and $\mathrm{E}_{\mathrm{a}}$ denotes pre-exponential factor, corrosion rate, universal gas constant, temperature in Kelvin and activation energy respectively. The activation energy required for the dissolution of metal was obtained from the slope of the plot log K vs $1 / \mathrm{T}$ for MS specimens in acid media, with and without inhibitor molecules (Fig. 3a and 4a). Thermodynamic parameters such as enthalpy $\left(\Delta \mathrm{H}^{*}\right)$ and entropy $\left(\Delta \mathrm{S}^{*}\right)$ changes were evaluated using transition state theory (Eq. (9) $)^{22}$

$$
\mathrm{K}=\left(\frac{\mathrm{RT}}{\mathrm{Nh}}\right) \exp \left(\frac{\Delta \mathrm{S}^{*}}{\mathrm{R}}\right) \exp \left(\frac{\Delta \mathrm{H}^{*}}{\mathrm{RT}}\right)
$$

where $\mathrm{h}$ and $\mathrm{N}$ are Planck's constant and Avogadro number respectively. The slope, $\frac{-\Delta \mathrm{H}^{*}}{2.303 \mathrm{R}}$ and intercept, $\log \left(\frac{\mathrm{R}}{2.303 \mathrm{Nh}}\right)+\left(\frac{\Delta \mathrm{S}^{*}}{2.303 \mathrm{R}}\right)$ obtained by plotting $\log \mathrm{K} / \mathrm{T}$ vs $1 / \mathrm{T}$ (Fig. $3 \mathrm{~b}$ and $4 \mathrm{~b}$ ). Table 3 represents the activation energy and thermodynamic parameters such as entropy of activation $\left(\Delta \mathrm{S}^{*}\right)$ and enthalpy of activation $\left(\Delta \mathrm{H}^{*}\right)$. It was observed that the activation energy of metal dissolution was high in the case of an acid solution containing an inhibitor molecule ${ }^{23}$. Also, it was found that $E_{\text {a }}$ increased with inhibitor concentration, which implies that dissolution of the metal was reduced with inhibitor concentration. The positive sign of the enthalpy of activation indicates the endothermic nature of metal dissolution. The $\Delta \mathrm{H}^{*}$ and $\Delta \mathrm{S}^{*}$ values were found to increase along with the rise in inhibitor concentration.

\subsection{Electrochemical impedance spectroscopic (EIS) studies}

The corrosion inhibition behaviour of DmChDa on MS in acid media was investigated using EIS at $28^{\circ} \mathrm{C}$. Fig. 5 and Fig. 6 (Nyquist and Bode plots) represent impedance spectra of mild steel in the absence and presence of $\mathrm{DmChDa}$ at various concentrations in $1 \mathrm{M} \mathrm{HCl}$ and $0.5 \mathrm{M} \mathrm{H}_{2} \mathrm{SO}_{4}$. The Nyquist plots of blank specimen and that treated with inhibitor were obtained to be semicircular, and the size of the semicircular plot increased upon the increasing concentration of inhibitor, which indicates the impedance enhancement of the MS with the concentration.

Table 3. Thermodynamic parameters of MS corrosion with and without DmChDa in acid media

\begin{tabular}{cccccc}
\hline Medium & $\begin{array}{c}\text { Conc } \\
(\mathrm{mM})\end{array}$ & $\begin{array}{c}\mathrm{E}_{\mathrm{a}} \\
\left(\mathrm{kJ} \mathrm{mol}^{-1}\right)\end{array}$ & $\mathrm{A}$ & $\begin{array}{c}\Delta \mathrm{H}^{*} \\
\left(\mathrm{~kJ} \mathrm{~mol}^{-1}\right)\end{array}$ & $\begin{array}{c}\Delta \mathrm{S}^{*} \\
\left(\mathrm{~J} \mathrm{~mol}^{-1} \mathrm{~K}^{-1}\right)\end{array}$ \\
\hline & Blank & 55.70 & $3.81 \times 10^{10}$ & 53.03 & -44.26 \\
& 0.2 & 102.76 & $1.41 \times 10^{18}$ & 100.12 & 100.64 \\
$1 \mathrm{M} \mathrm{HCl}$ & 0.4 & 103.55 & $1.68 \times 10^{18}$ & 100.91 & 102.10 \\
& 0.6 & 107.13 & $6.44 \times 10^{18}$ & 104.48 & 113.26 \\
& 0.8 & 109.73 & $1.56 \times 10^{19}$ & 107.09 & 120.65 \\
& 1.0 & 119.48 & $5.24 \times 10^{20}$ & 116.83 & 149.85 \\
\hline $0.5 \mathrm{M} \mathrm{H}_{2} \mathrm{SO}_{4}$ & Blank & 33.14 & $2.08 \times 10^{7}$ & 30.50 & -106.71 \\
& 0.2 & 46.10 & $2.46 \times 10^{9}$ & 43.46 & -67.03 \\
& 0.4 & 69.12 & $1.04 \times 10^{13}$ & 66.48 & 2.38 \\
& 0.6 & 79.66 & $4.75 \times 10^{14}$ & 77.02 & 34.16 \\
& 0.8 & 96.33 & $1.96 \times 10^{17}$ & 93.69 & 84.25 \\
\hline
\end{tabular}



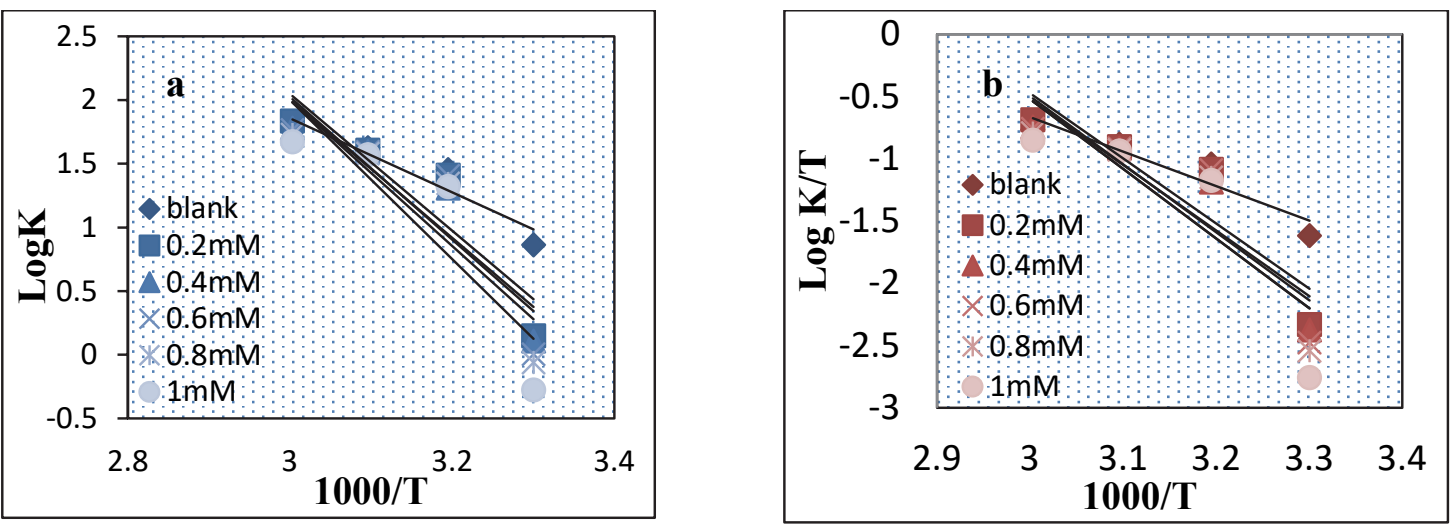

Fig. 3. Plot of a) $\log \mathrm{K}$ vs $1000 / \mathrm{T}$ b) $\log \mathrm{K} / \mathrm{T}$ vs $1000 / \mathrm{T}$ with and without $\mathrm{DmChDa}$ in $1 \mathrm{M} \mathrm{HCl}$
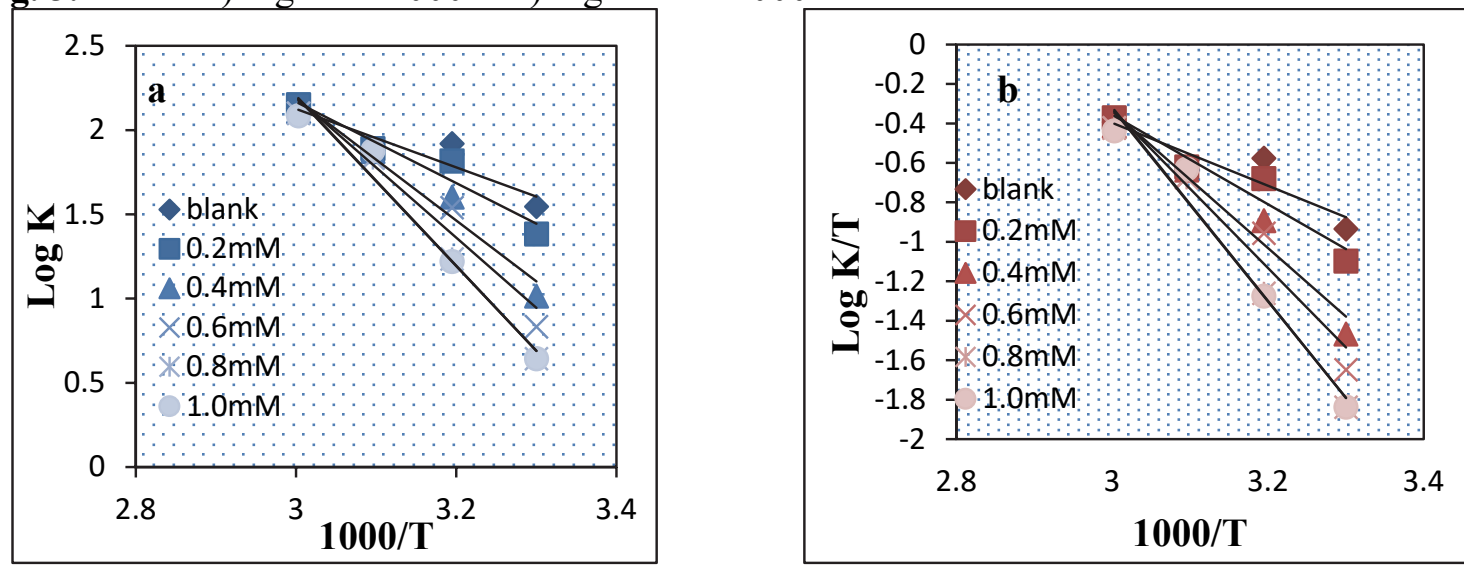

Fig. 4. Plot of a) $\log \mathrm{K}$ vs $1000 / \mathrm{T}$ b) $\log \mathrm{K} / \mathrm{T}$ vs $1000 / \mathrm{T}$ with and without $\mathrm{DmChDa}$ in $0.5 \mathrm{M} \mathrm{H}_{2} \mathrm{SO}_{4}$

The corrosion inhibition efficiency also increased with concentration. Randles circuit was found to be the most fit equivalent circuit for Nyquist plots (Fig. 7) which consisted of charge transfer resistance $\mathrm{R}_{\mathrm{ct}}$, double layer capacitance $\mathrm{C}_{\mathrm{dl}}$ and solution resistance $\mathrm{R}_{\mathrm{s}}{ }^{24}$ Constant phase element (CPE) was inserted into the circuit in preference to pure double layer capacitance to lower the effects due to deformities on the surface of metal as shown in Fig. 8. The impedance of CPE can be expressed as ${ }^{25}$

$$
\mathrm{Z}_{\mathrm{CPE}}=\frac{1}{\mathrm{Y}_{0}(\mathrm{j} \omega)^{\mathrm{n}}},
$$

where $\mathrm{Y}_{0}, \mathrm{n}, \mathrm{w}$ and $\mathrm{j}$ denotes the magnitude of $\mathrm{CPE}$, exponent (phase shift), angular frequency and imaginary unit respectively. Based on the values of $n, C P E$ can be capacitance, inductance and resistance. ${ }^{26}$ It was observed that the values of $n$ were between 0.75 and 1.0 , indicating the capacitance nature of CPE. The parameters CPE, $R_{c t}$ and the percentage of corrosion inhibition efficiency ( $\prod_{\mathrm{EIS}} \%$ ) of $\mathrm{DmChDa}$ are listed in Table 4.

Table 4. Impedance data of MS specimen with and without DmChDa in acid media

\begin{tabular}{ccccccc}
\hline $\begin{array}{c}\text { Conc } \\
(\mathrm{mM})\end{array}$ & \multicolumn{3}{c}{$1 \mathrm{M} \mathrm{HCl}$} & \multicolumn{3}{c}{$0.5 \mathrm{M} \mathrm{H}_{2} \mathrm{SO}_{4}$} \\
\cline { 2 - 7 } & $\begin{array}{c}\mathrm{R}_{\mathrm{ct}} \\
\left(\Omega \mathrm{cm}^{2}\right)\end{array}$ & $\begin{array}{c}\mathrm{C}_{\mathrm{dl}} \\
\left(\mu \mathrm{Fcm}^{-2}\right)\end{array}$ & $\prod_{\mathrm{EIS} \%}$ & $\begin{array}{c}\mathrm{R}_{\mathrm{ct}} \\
\left(\Omega \mathrm{cm}^{2}\right)\end{array}$ & $\begin{array}{c}\mathrm{C}_{\mathrm{dl}} \\
\left(\mu \mathrm{Fcm}^{-2}\right)\end{array}$ & $\prod_{\mathrm{EIS} \%}$ \\
\hline 0.0 & 29.1 & 105 & - & 7.96 & 113 & - \\
\hline 0.2 & 181 & 81.8 & 83.92 & 9.10 & 72.6 & 12.53 \\
0.4 & 200 & 81.6 & 85.45 & 12.8 & 66.6 & 37.81 \\
0.6 & 232 & 99.4 & 87.45 & 14.3 & 71.6 & 44.33 \\
0.8 & 253 & 92.9 & 88.49 & 14.7 & 62.3 & 45.85 \\
1.0 & 308 & 65.4 & 90.55 & 16.7 & 54.6 & 52.33 \\
\hline
\end{tabular}


Charge transfer resistance $\left(\mathrm{R}_{\mathrm{ct}}\right)$ was increased, whereas capacitance $\left(\mathrm{C}_{\mathrm{dl}}\right)$ value was reduced with inhibitor concentration in both cases. High value of charge transfer resistance was observed in $1 \mathrm{M} \mathrm{HCl}$. The decrease in $\mathrm{C}_{\mathrm{dl}}$ values was attributed to the lowering of local dielectric constant and/or increase in the thickness of electrical double layer. ${ }^{27}$ The maximum corrosion inhibition efficiencies of $90.55 \%$ and $52.33 \%$ were observed at $1 \mathrm{mM}$ concentration of $\mathrm{DmChDa}$ in $1 \mathrm{M} \mathrm{HCl}$ and $0.5 \mathrm{M} \mathrm{H}_{2} \mathrm{SO}_{4}$ respectively.
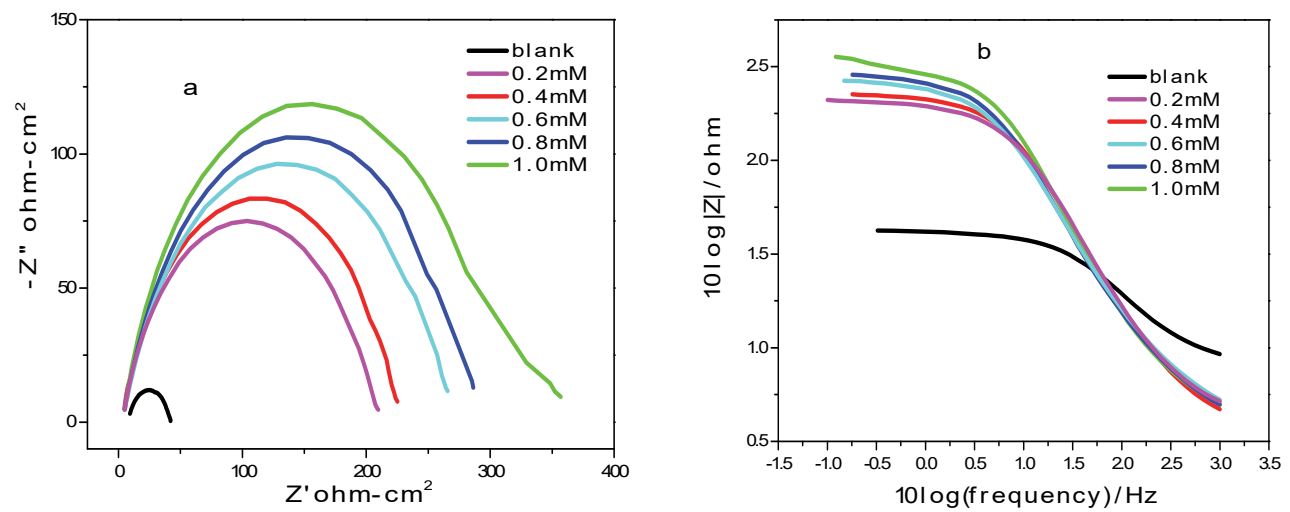

Fig. 5. Impedance spectra a) Nyquist and b) Bode plot of MS coupons with and without DmChDa in $1 \mathrm{M} \mathrm{HCl}$
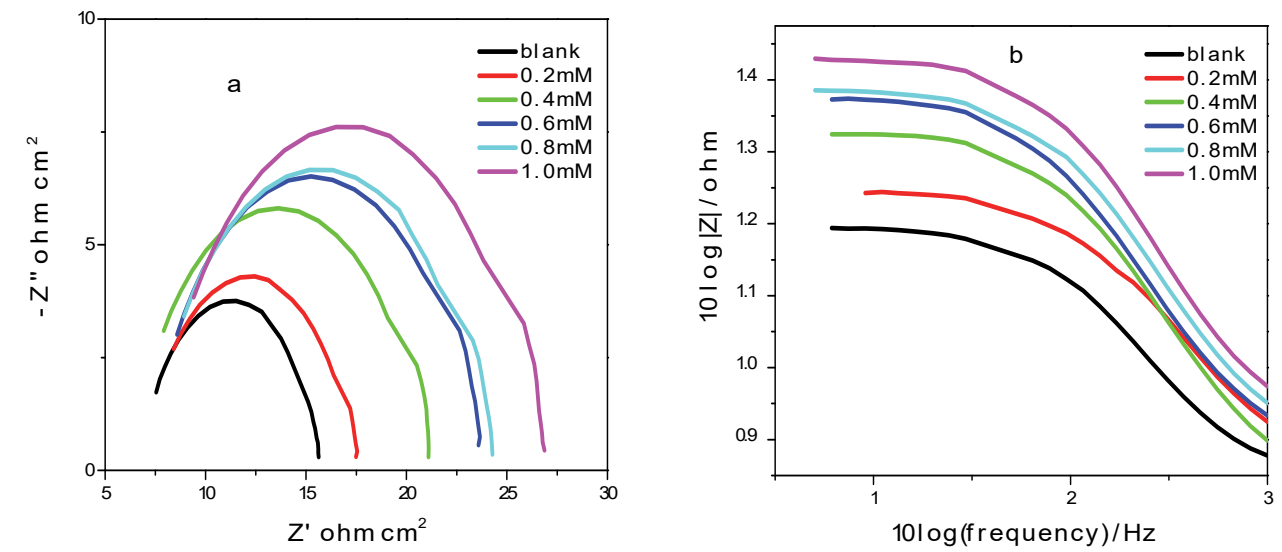

Fig. 6. Impedance spectra a) Nyquist and b) Bode plot of MS coupons with and without DmChDa in $0.5 \mathrm{M} \mathrm{H}_{2} \mathrm{SO}_{4}$

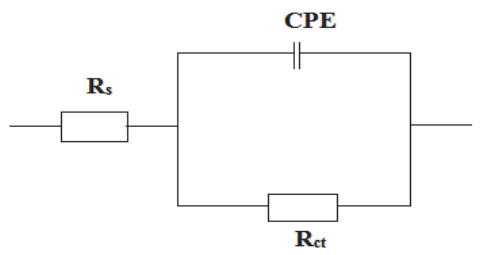

Fig. 7. Randles circuit used for EIS measurements.

\subsection{Potentiodynamic polarization studies}

The criteria such as corrosion current densities ( $\left.\mathrm{I}_{\text {corr }}\right)$, corrosion potential $\left(\mathrm{E}_{\text {corr }}\right)$, anodic slope $\left(\mathrm{b}_{\mathrm{a}}\right)$, cathodic slope $\left(b_{c}\right)$ and inhibition efficiency $\left(\eta_{\mathrm{pol}} \%\right)$ of $\mathrm{DmChDa}$ in $1 \mathrm{M} \mathrm{HCl}$ and $0.5 \mathrm{M} \mathrm{H}_{2} \mathrm{SO}_{4}$ are given in Table 5. Polarization curves are shown in Fig. 8. Polarization data reveals that corrosion current density decreased with the rise in concentration of $\mathrm{DmChDa}$. As a result, the percentage of inhibition 
efficiency also increased. A maximum inhibition efficiency of $95.59 \%$ and $44.33 \%$ were shown by DmChDa at $1 \mathrm{mM}$ concentration in $1 \mathrm{M} \mathrm{HCl}$ and $0.5 \mathrm{M} \mathrm{H}_{2} \mathrm{SO}_{4}$ respectively. The $b_{a}$ and $b_{c}$ values indicated that addition of $\mathrm{DmChDa}$ to acid media affected both cathodic and anodic parts of the curves and hence acted as a mixed type inhibitor. ${ }^{28-29}$

Considerable difference was noticed between the corrosion inhibition efficiency of DmChDa in gravimetric and electrochemical studies (EIS and potentiodynamic polarization) in $0.5 \mathrm{M} \mathrm{H}_{2} \mathrm{SO}_{4}$ medium. DmChDa consists of two $-\mathrm{C}=\mathrm{N}$ - linkages which are responsible for hydrolysis in acid medium. By using UV-visible spectroscopy, it was confirmed that slow hydrolysis of $\mathrm{DmChDa}$ is occurring in $0.5 \mathrm{M} \mathrm{H}_{2} \mathrm{SO}_{4}$ medium. It can be supposed that appreciable degradation in the structure of $\mathrm{DmChDa}$ was not happening within 1-2 $\mathrm{h}$. On keeping the inhibitor for a period of $24 \mathrm{~h}$ complete hydrolysis of the molecule takes place and the parent compounds 5-5-dimethyl-1,3-cyclohexanedione (Dm) and aniline (An) regenerated were responsible for the high inhibition efficiency. The parent compounds itself have appreciable inhibition efficiency in $0.5 \mathrm{M} \mathrm{H}_{2} \mathrm{SO}_{4}$ (Table 2). The enhanced inhibition efficiency of $\mathrm{DmChDa}$ in gravimetric study than electrochemical study was attributed to the net effect of inhibition efficiency of both parent compounds formed during hydrolysis. Even though there is a probability for hydrolysis in $1 \mathrm{M} \mathrm{HCl}$ medium the corrosion inhibition efficiency of DmChDa in gravimetric and electrochemical studies follows the same trend. This may be due to the higher adsorption tendency of $\mathrm{DmChDa}$ on $\mathrm{Cl}^{-}$ion, which is strongly bind to mild steel surface instead of its hydrolysis.

\subsection{Electrochemical noise studies}

Electrochemical noise measurements was conducted by immersing two identical mild steel electrodes and calomel electrode (as reference electrode) in an acid medium in the presence and absence of $\mathrm{DmChDa}$ for a period of 1200s. Current noise for MS in the absence and presence of DmChDa $(1 \mathrm{mM})$ in the acid medium is shown in Figure 9. From the figure, it is clear that blank specimen exhibits higher mean value of current noise in respect of the specimen dipped in an acid medium containing inhibitor molecules, and the mean value of current noise in $0.5 \mathrm{M} \mathrm{H}_{2} \mathrm{SO}_{4}$ was greater than in $1 \mathrm{M} \mathrm{HCl}$ medium, which reflects the greater protective power of $\mathrm{DmChDa}$ in $1 \mathrm{M} \mathrm{HCl}$ medium. ${ }^{30}$

The frequency domain analysis of noise measurement gave the PSD (Power Spectral Density) of different systems, which is represented in Figure 10. On close examination of PSD plots, it is clear that at all frequencies, the values of current noise are comparatively large for blank metal specimen than for metal immersed in acid solution containing DmChDa which suggests that localised corrosion of mild steel is occurring in acid solution without an inhibitor molecule. ${ }^{31}$

Pitting index is a measure of resisting power to localised pitting corrosion. The pitting index curves are shown in Fig. 11. The amplitude of the pitting index curve corresponding to blank metal specimen is lower than metal specimens treated with acid solution containing inhibitors. This implies that acid solution containing an inhibitor molecule has higher resistance to pitting corrosion.
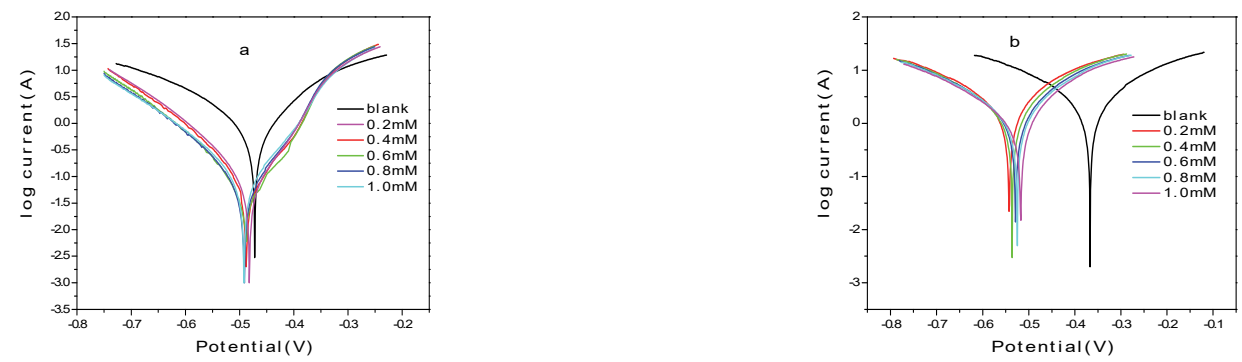

Fig. 8. Tafel plots of MS coupons with and without $\mathrm{DmChDa}$ in a) $1 \mathrm{M} \mathrm{HCl}$ and b) $0.5 \mathrm{M} \mathrm{H}_{2} \mathrm{SO}_{4}$ 
Table 5. Polarization data of MS specimen with and without DmChDa in acid media

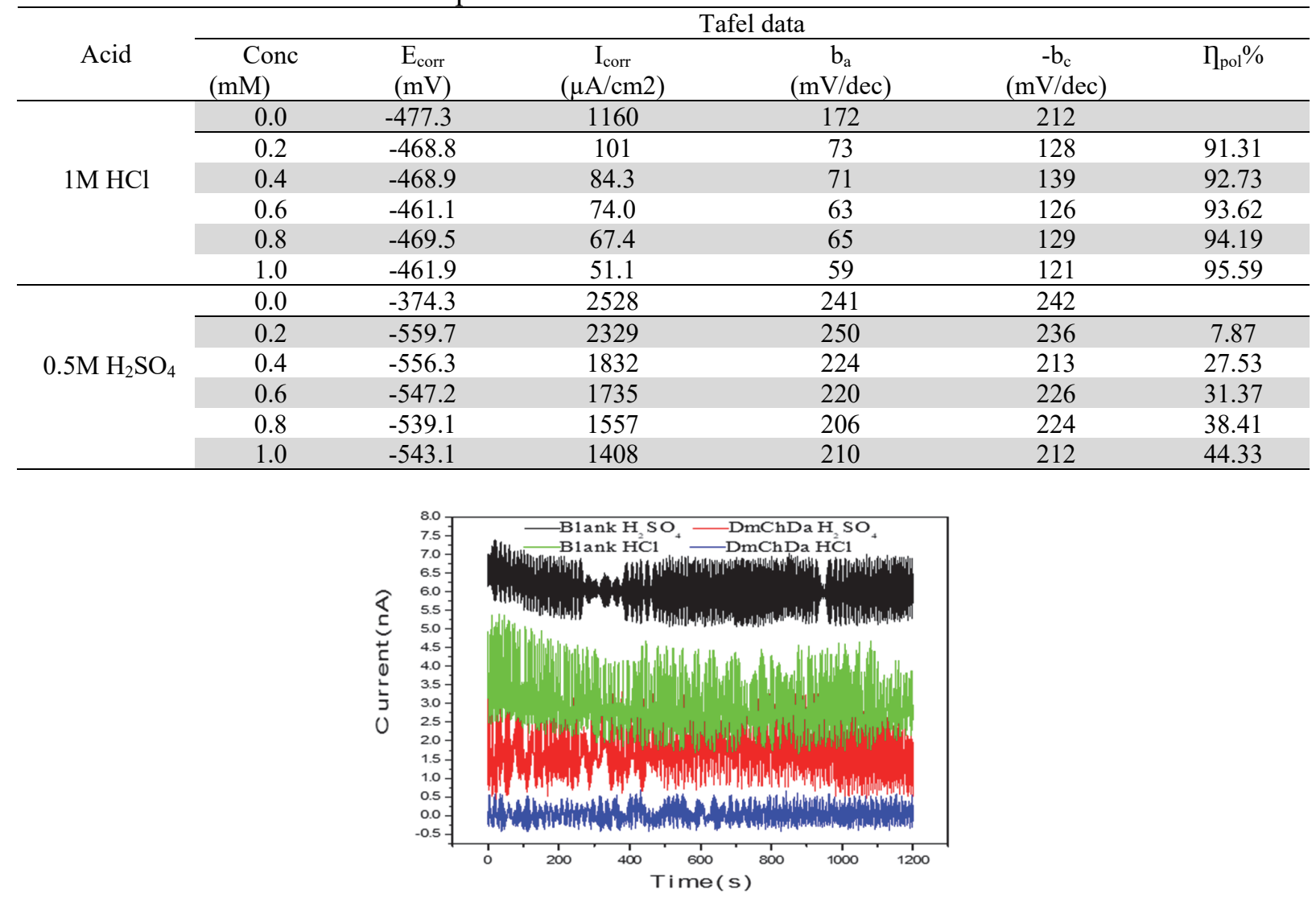

Fig. 9. Current noise for MS in the absence and presence of $\mathrm{DmChDa}(1 \mathrm{mM})$ in acid media

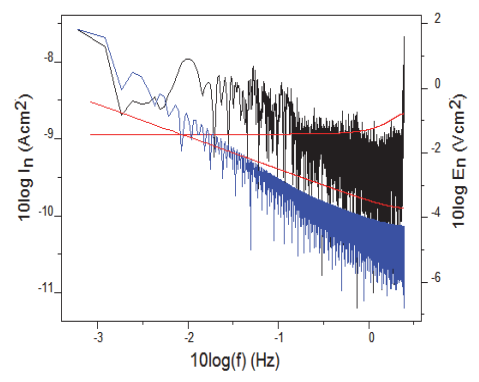

(a)

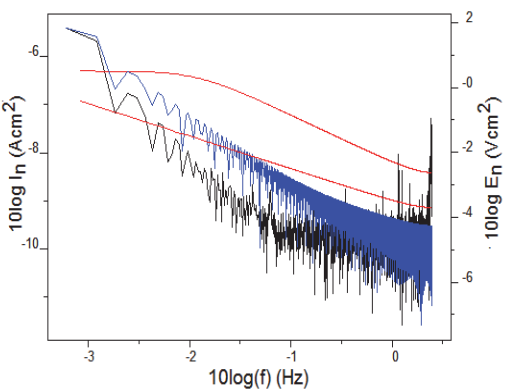

(C)

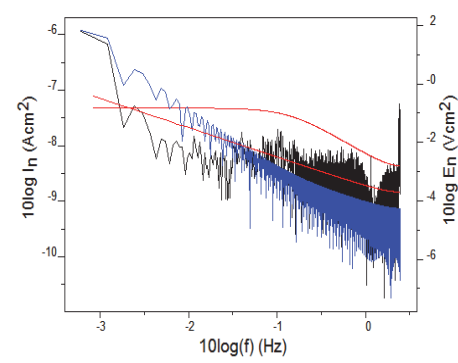

(b)

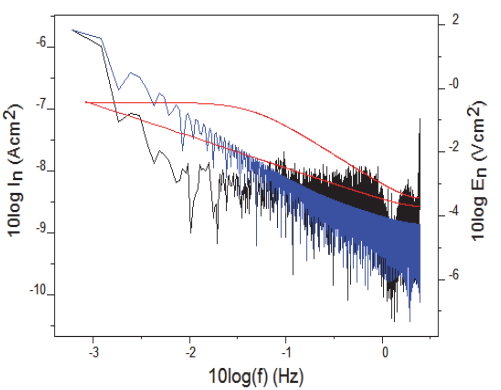

(d)

Figure 10. Power spectral density (voltage and current) of $\mathrm{MS}$ a) blank $1 \mathrm{M} \mathrm{HCl} \mathrm{b)} \mathrm{in} \mathrm{the} \mathrm{presence} \mathrm{of}$ DmChDa $(1 \mathrm{mM})$ in $1 \mathrm{M} \mathrm{HCl}, \mathrm{c})$ blank $0.5 \mathrm{M} \mathrm{H}_{2} \mathrm{SO}_{4}$ and d) in the presence of DmChDa $(1 \mathrm{mM})$ in $0.5 \mathrm{M}$ $\mathrm{H}_{2} \mathrm{SO}_{4}$. 


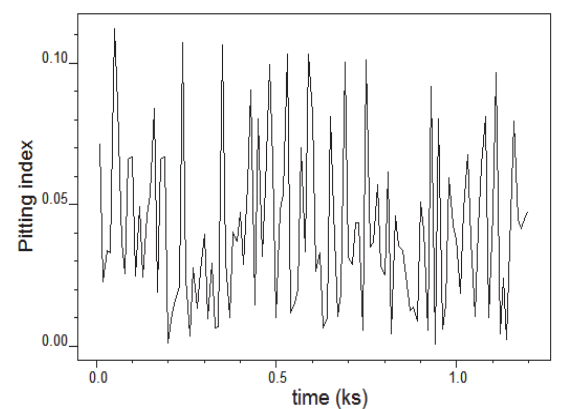

(a)

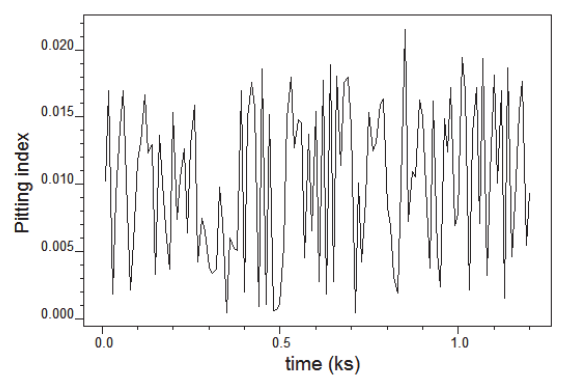

(c)

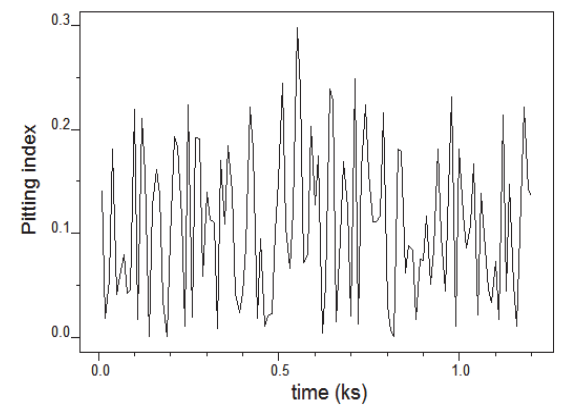

(b)

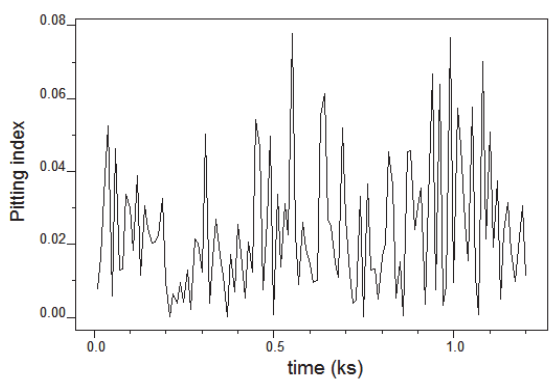

(d)

Fig. 11. Pitting index curve of $\mathrm{MS}$ a) blank $1 \mathrm{M} \mathrm{HCl} \mathrm{b)} \mathrm{in} \mathrm{the} \mathrm{presence} \mathrm{of} \mathrm{DmChDa}(1 \mathrm{mM})$ in $1 \mathrm{M} \mathrm{HCl}$ c) blank $0.5 \mathrm{M} \mathrm{H}_{2} \mathrm{SO}_{4}$ and d) in the presence of $\mathrm{DmChDa}(1 \mathrm{mM})$ in $0.5 \mathrm{M} \mathrm{H}_{2} \mathrm{SO}_{4}$

\subsection{Scanning electron microscopy (SEM)}

In order to determine the surface morphology of MS coupons, scanning electron microscopy was conducted. Fig. 12 (a-e) represents the SEM images of bare metal, mild steel coupon treated with $1 \mathrm{M}$ $\mathrm{HCl}$, treated with $0.5 \mathrm{M} \mathrm{H}_{2} \mathrm{SO}_{4}$, treated with $\mathrm{DmChDa}(1 \mathrm{mM})$ in $1 \mathrm{M} \mathrm{HCl}$ and treated with $\mathrm{DmChDa}$ $(1 \mathrm{mM})$ in $0.5 \mathrm{M} \mathrm{H}_{2} \mathrm{SO}_{4}$ respectively.

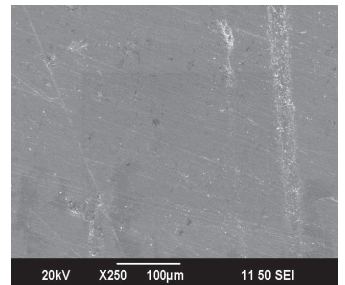

(a)

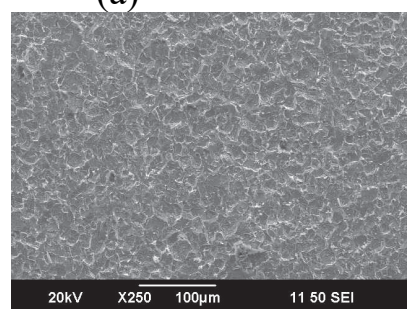

(d)

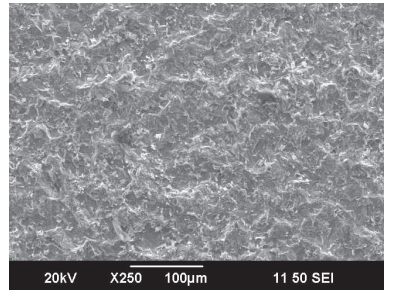

(b)

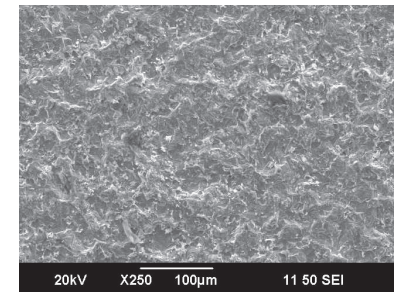

(c)

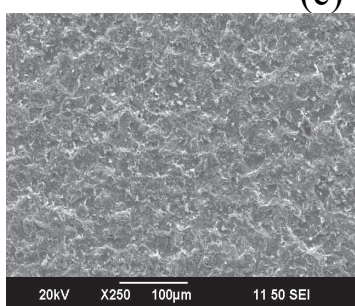

(e)

Fig. 12. SEM analysis of MS coupons before and after $24 \mathrm{~h}$ immersion (a) bare metal, (b) blank (1M $\mathrm{HCl})$, (c) blank $\left(0.5 \mathrm{M} \mathrm{H}_{2} \mathrm{SO}_{4}\right)$, (d) treated with $\mathrm{DmChDa}(1 \mathrm{mM})$ in $1 \mathrm{M} \mathrm{HCl}$, (e) treated with DmChDa $(1 \mathrm{mM})$ in $0.5 \mathrm{M} \mathrm{H}_{2} \mathrm{SO}_{4}$ 
There exists a remarkable difference between the surface of a polished mild steel specimen and the one treated with acid solution ${ }^{4}$. It is clear that the mild steel surface reacted with acid medium from its erratic and rough structure. A remarkable change in the surface morphology of MS was observed after adding an inhibitor molecule into an aggressive medium. In the presence of $1 \mathrm{mM}$ concentration of $\mathrm{DmChDa}$ in both acid media, the corrosion rate was found to decrease, and the surface became less corroded. This is a clear indication of the formation of a protective layer of inhibitor molecules on mild steel surface.

\section{Conclusions}

1. The Schiff base DmChDa is a best inhibitor of corrosion for mild steel in $1 \mathrm{M} \mathrm{HCl}$

2. The maximum inhibition potency of DmChDa in $1 \mathrm{M} \mathrm{HCl}$ and $0.5 \mathrm{M} \mathrm{H}_{2} \mathrm{SO}_{4}$ was $92.63 \%$ and $87.52 \%$ respectively according to weight loss measurements.

3. The contradiction between the corrosion inhibition efficiency of $\mathrm{DmChDa}$ in gravimetric and electrochemical studies is due to the complete hydrolysis of the inhibitor over a period of $24 \mathrm{~h}$.

4. DmChDa exhibits high inhibition efficiency than the corresponding parent compounds.

5. The adsorption of $\mathrm{DmChDa}$ on a mild steel surface, in $1 \mathrm{M} \mathrm{HCl}$ and $0.5 \mathrm{M} \mathrm{H}_{2} \mathrm{SO}_{4}$ obeys Langmuir and El-Awady isotherms respectively.

6. $\Delta \mathrm{G}^{0}$ ads values indicate that the adsorption behaviour involves both chemical and electrostatic interaction in $1 \mathrm{M} \mathrm{HCl}$ whereas in $0.5 \mathrm{M} \mathrm{H}_{2} \mathrm{SO}_{4}$ the adsorption behaviour is mainly by chemical interaction

7. High activation energy of corrosion in the presence of inhibitor implies that dissolution of metal decreased with inhibitor concentration due to adsorption of inhibitor on mild steel surface.

8. Polarization data reveals that $\mathrm{DmChDa}$ acts as a mixed type inhibitor in both acid media.

9. At all frequencies, the values of current noise are comparatively large for blank metal specimen than for metal immersed in an acid solution containing DmChDa. This clearly suggests that localised corrosion of mild steel is occurring in an acid solution without an inhibitor molecule.

10. SEM analysis confirms that the inhibitor gets adsorbed on the MS surface.

\section{Acknowledgement}

Authors are grateful to Council of Scientific \& Industrial Research (CSIR) for providing financial assistance for the research work.

\section{Materials and methods}

\subsection{Synthesis and characterization of DmChDa}

Hot ethanolic solution of 5,5-dimethyl-1,3-cyclohexanedione $(0.01 \mathrm{~mol})$ was added dropwise to a stirred solution containing $0.02 \mathrm{~mol}$ of aniline in ethanol. The mixture was refluxed for about $3 \mathrm{~h}$ and cooled. The yellow coloured precipitate formed was filtered, washed with distilled water and dried. Fig.13 shows the molecular structure of DmChDa and its tautomer. Anal.calcd for $\mathrm{C}_{20} \mathrm{H}_{22} \mathrm{~N}_{2}: \mathrm{C}, 82.7$; H, 7.5; N, 9.6\%. Found. C, 81.3; H, 6.9; N, 8.9\%; IR (KBr): $v_{\mathrm{C}=\mathrm{N}} 1564 \mathrm{~cm}^{-1} .{ }^{1} \mathrm{H}$ NMR: $\delta_{\mathrm{NH}} 6.1 . \delta_{\mathrm{CH} 3}$ 1.0. ${ }^{13} \mathrm{C}$ NMR: $\delta_{\mathrm{CH}} 3$ 28.3. Mass: $\mathrm{M}^{+}$peak was absent, base peak $\left[\mathrm{C}_{11} \mathrm{H}_{13} \mathrm{~N}\right]{ }^{+} \mathrm{m} / \mathrm{z}: 159 . \mathrm{m} . \mathrm{p} .=152{ }^{0} \mathrm{C}$.

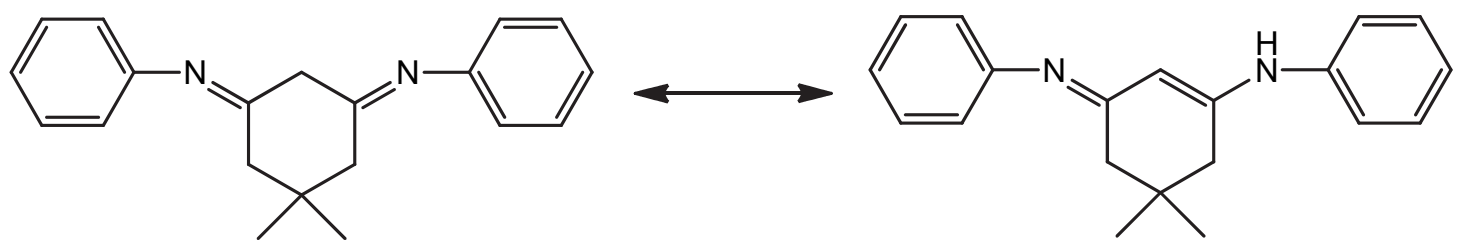

Fig. 13. Tautomeric structure of $N, N^{\prime}$-(5,5-dimethylcyclohexane-1,3-diylidene)dianiline. 


\subsection{Solutions}

The acid solution required for conducting corrosion monitoring techniques was prepared from analytical grade acid (Merck) by diluting it with distilled water. The inhibitor concentration employed for the study has the concentration range $0.2 \mathrm{mM}-1.0 \mathrm{mM}$.

\subsection{Weight loss studies}

Mild steel (MS) strips having an exposed area of $1 \times 1 \times 0.096 \mathrm{~cm}$ were employed for conducting weight loss studies. Prior to treatment, the strips were polished with $\mathrm{SiC}$ papers having grades 100, 200, 400, 600, 800, 1000, 1500 and 2000. Then washed with acetone followed by distilled water and dried. After measuring thickness and area, the MS strips were immersed in $50 \mathrm{ml}$ acid solution at $28^{0} \mathrm{C}$ with the help of fishing lines. The corrosion rate $(v)$ was calculated by measuring the weight loss of the mild steel strip after $24 \mathrm{~h}$ using following equation ${ }^{32-33}$.

$$
v=\frac{\mathrm{KW}}{\mathrm{DSt}}
$$

where $\mathrm{K}=87600, \mathrm{~W}, \mathrm{D}, \mathrm{S}$ and $\mathrm{t}$ implies average weight loss of coupon $(\mathrm{g})$, density of mild steel $\left(\mathrm{g} \mathrm{cm}^{-}\right.$ $\left.{ }^{3}\right)$, total area of specimen $\left(\mathrm{cm}^{2}\right)$ and exposure time $(\mathrm{h})$ respectively. The percentage of inhibition efficiency was calculated using the following equation ${ }^{34-35}$

$$
\eta_{\mathrm{w}} \%=\frac{\mathrm{v}_{0}-\mathrm{v}}{\mathrm{v}_{0}} \times 100,
$$

where $\mathrm{v}_{0}$ and $\mathrm{v}$ describe corrosion rate of specimens in contact with the acid solution without and with inhibitor respectively.

\subsection{Electrochemical impedance spectroscopic (EIS) studies}

Ivium compactstat-e electrochemical system was utilized for impedance study. The cell consists of three-electrode assembly of saturated calomel electrode (SCE), platinum electrode having $1 \mathrm{~cm}^{2}$ area and metal specimen with an exposed area of $1 \mathrm{~cm}^{2}$ as reference electrode, counter electrode and working electrode respectively. Metal specimen was immersed in electrolyte solution (acid solution) prior to each measurement for 30 minutes. EIS measurements were determined at a constant potential (OCP) in the frequency range $1 \mathrm{KHz}-100 \mathrm{MHz}$ with an amplitude of $10 \mathrm{mV}$ as excitation signal. The analysis of impedance plots gave charge transfer resistance. The corrosion inhibition efficiency was determined using the following expression ${ }^{36-37}$

$$
\prod_{\mathrm{EIS}} \%=\frac{\text { Rct }-\mathrm{R}^{\prime} \mathrm{ct}}{\mathrm{Rct}} \times 100
$$

where $R_{c t}$ and $R_{\text {ct }}$ denote charge transfer resistance of the metal specimen immersed in acid medium with and without $\mathrm{DmChDa}$.

\subsection{Potentiodynamic polarization studies}

The MS specimens were subjected to Tafel extrapolation analysis after immersing in an acid solution with and without DmChDa for a period of 30 minutes. As mentioned in EIS studies, a threeelectrode system was used in polarization studies. The analyses were carried out by changing the potential of the working electrode from -250 to $+250 \mathrm{mV}$ relative to the corrosion potential ( $\mathrm{E}_{\text {corr }}$ ) at a scan rate of $1 \mathrm{mV} / \mathrm{sec}$. Corrosion current density $\left(\mathrm{I}_{\text {corr }}\right)$ was obtained from Tafel plots from which the percentage of inhibition efficiency $\left(\eta_{\text {pol }} \%\right)$ was calculated as described below ${ }^{38-39}$ 
Пpol \% $=\frac{\text { Icorr }-\mathrm{I}^{\prime} \text { corr }}{\text { Icorr }} \times 100$

where $I_{\text {corr }}$ and I' corr indicate corrosion current densities of the metal specimen immersed in acid medium without and with DmChDa.

\subsection{Electrochemical noise studies}

Electrochemical noise measurements were carried out in a three-electrode system consisting of two mild steel electrodes having $1 \mathrm{~cm}^{2}$ area and a saturated calomel electrode ${ }^{40}$. The analysis was executed with the help of Ivium Compactstat-e electrochemical system controlled by iviumsoft software. All electrochemical noise analyses were performed for a period of 1200 s.

\subsection{Scanning electron microscopy}

Scanning electron microscope (JEOL Model JSM - 6390LV) was used to study the surface nature of the mild steel specimens after treatment with acid solution in the presence and absence of DmChDa for $24 \mathrm{~h}$.

\section{References}

1. Wang X., Wang Y., Wang Q., Wan Y., Huang X., and Jing C. (2018) Viburnum Sargentii Koehne fruit extract as corrosion inhibitor for mild steel in acidic solution. Int. J. Electrochem. Sci. 13 (2018) 5228-5242.

2. Ansari K. R., Quraishi M. A., and Singh A. (2015) Corrosion inhibition of mild steel in hydrochloric acid by some pyridine derivatives: An experimental and quantum chemical study. J. Ind. Eng. Chem. 25 89-98.

3. Singh A. K., Shukla S. K., Quraishi M. A., and Ebenso E. E. (2012) Investigation of adsorption characteristics of N,N'-[(methylimino)dimethylidyne ]di-2,4-xylidine as corrosion inhibitor at mild steel/sulphuric acid interface. J. Taiwan. Inst. Chem. E. 43 (3) 463-472.

4. Ragi K., Joby Thomas K., Vinod P. Raphael., Sini Varghese C., and Binsi M. Paulson. (2019) Synthesis, cyclic voltammetric, electrochemical and gravimetric corrosion inhibition investigations of Schiff base derived from 5, 5-dimethyl-1,3-cyclohexanedione and 2-aminophenol on mild steel in $1 \mathrm{M} \mathrm{HCl}$ and $0.5 \mathrm{M} \mathrm{H}_{2} \mathrm{SO}_{4}$. Int. J. Electrochem. 2019 1-13.

5. Ramya K., Mohan R., Anupama K.K., and Joseph A. (2015) Electrochemical and theoretical studies on the synergistic interaction and corrosion inhibition of alkyl benzimidazoles and thiosemicarbazide pair on mild steel in hydrochloric acid. Mater. Chem. Phys. 149-150 (2015) 632647.

6. Ahamad I., Prasad R., and Quraishi M. A. (2010) Experimental and quantum chemical characterization of the adsorption of some Schiff base compounds of phthaloyl thiocarbohydrazide on the mild steel in acid solutions. Mater. Chem. Phys. 124 (2-3)1155-1165.

7. Ansari K. R., and Quraishi M. A. (2015) Isatin derivatives as a non-toxic corrosion inhibitor for mild steel in $20 \% \mathrm{H}_{2} \mathrm{SO}_{4}$. Corros. Sci. 95 62-70.

8. John S., and Joseph A. (2012) Electro analytical, surface morphological and theoretical studies on corrosion inhibition behaviour of different 1,2,4-triazole precursors on mild steel in $1 \mathrm{M}$ hydrochloric acid. Mater. Chem. Phys. 133 1083-1091.

9. Singh P., Srivastava V., and Quraishi M.A. (2016) Novel quinoline derivatives as green corrosion inhibitors for mild steel in acidic medium: Electrochemical, SEM, AFM, and XPS studies. J. Mol. Liq. 216 164-173.

10. Mallaiya K., Subramanian R., Srikandan S., Gowri S., Rajasekaran N., and Selvaraj A. (2011) Electrochemical characterization of the protective film formed by the unsymmetrical Schiff's base on the mild steel surface in acid media. Electrochim. Acta. 56 (11) 3857-3863. 
11. Ansari K.R., Quraishi M.A., and Singh A. (2014) Schiff's base of pyridyl substituted triazoles as new and effective corrosion inhibitors for mild steel in hydrochloric acid solution. Corros. Sci. 79 5-15.

12. Soltani N., Behpour M., Ghoreishi S.M., and Naeimi H. (2010) Corrosion inhibition of mild steel in hydrochloric acid solution by some double Schiff bases, Corros. Sci. 52 (4) 1351-1361.

13. Raphael V. P., Thomas K. J., Shaju K. S., and Paul A. (2014) Corrosion inhibition investigations of 3-acetylpyridine semicarbazone on carbon steel in hydrochloric acid medium. Res. Chem. Intermediat. 40 2689-2701.

14. Saha S. K., Dutta A., Ghosh P., Sukul D., and Banerjee P. (2015) Adsorption and corrosion inhibition effect of Schiff base molecules on the mild steel surface in $1 \mathrm{M} \mathrm{HCl}$ medium: A combined experimental and theoretical approach. Phys. Chem. Chem. Phys. 17 (8) 5679-5690.

15. Ahamad I., Prasad R., and Quraishi M.A. (2010) Inhibition of mild steel corrosion in acid solution by Pheniramine drug: Experimental and theoretical study. Corros. Sci. 52 (9) 3033-3041.

16. Yadav D. K., Chauhan D.S., Ahamad I., and Quraishi M.A. (2013) Electrochemical behavior of steel/acid interface:adsorption and inhibition effect of oligomeric aniline. RSC Adv. 3 (2) 632.

17. Ansari K. R., and Quraishi M.A. (2013) Bis-Schiff bases of isatin as new and environmentally benign corrosion inhibitor for mild steel. J. Ind. Eng. Chem. 20 (5) 2819-2829.

18. Issaadi S., Douadi T., Zouaoui A., Chafaa S., Khan M.A., and Bouet G. (2011) Novel thiophene symmetrical Schiff base compounds as corrosion inhibitor for mild steel in acidic media. Corros Sci. 53 (4) 1484-1488.

19. Ansari K. R., Quraishi M.A., and Singh A. (2014) Schiff's base of pyridyl substituted triazoles as new and effective corrosion inhibitors for mild steel in hydrochloric acid solution, Corros Sci. 795 15.

20. Badr G. E. (2009) The role of some thiosemicarbazide derivatives as corrosion inhibitors for Csteel in acidic medium. Corros Sci. 51 2529-2536.

21. Yadav D. K., Quraishi M. A., and Maiti B. (2012) Inhibition effect of some benzylidenes on mild steel in $1 \mathrm{M} \mathrm{HCl}$ : An experimental and theoretical correlation. Corros Sci. 55 254-266.

22. Hegazy M.A., Hasan A. M., Emara M.M., Bakr M. F., and Youssef A. H. (2012) Evaluating four synthesized Schiff bases as corrosion inhibitors on the carbon steel in $1 \mathrm{M}$ hydrochloric acid. Corros. Sci. 65 67-76.

23. Verma C. B., Ebenso E. E., Bahadur I., Obot I. B., and Quraishi M.A. (2015) 5-(Phenylthio)-3Hpyrrole-4-carbonitriles as effective corrosion inhibitors for mild steel in $1 \mathrm{M} \mathrm{HCl}$ : Experimental and theoretical investigation. J. Mol. Liq. 212 209-218.

24. Verma C., Quraishi M. A., and Singh A. (2015) 2-Aminobenzene-1,3-dicarbonitriles as green corrosion inhibitor for mild steel in $1 \mathrm{M} \mathrm{HCl}$ : Electrochemical, thermodynamic, surface and quantum chemical investigation. J Taiwan Inst Chem E. 49 229-239.

25. Singh A. K., and Quraishi M.A. (2011) Investigation of the effect of disulfiram on corrosion of mild steel in hydrochloric acid solution. Corros. Sci. 53 (4) 1288-1297.

26. Chaitra T. K., Mohana K. N. S., and Tandon H. C. (2015) Thermodynamic, electrochemical and quantum chemical evaluation of some triazole Schiff bases as mild steel corrosion inhibitors in acid media. J. Mol. Liq. 211 1025-1038.

27. Deng Q., Shi H. W., Ding N. N., Chen B. Q., He X. P., Liu G., Tang Y., Long Y. T., and Chen G. R. (2012) Novel triazolyl bis-amino acid derivatives readily synthesized via click chemistry as potential corrosion inhibitors for mild steel in HCl. Corros. Sci. 57 220-227.

28. Tao Z., He W., Wang S., Zhang S., and Zhou G. (2012) A study of differential polarization curves and thermodynamic properties for mild steel in acidic solution with nitrophenyltriazole derivative. Corros. Sci. 60 205-213.

29. Ahamad I., Prasad R., and Quraishi M.A. (2010) Thermodynamic, electrochemical and quantum chemical investigation of some Schiff bases as corrosion inhibitors for mild steel in hydrochloric acid solutions. Corros. Sci. 52 (3) 933-942.

30. Issa R. M., Awad M. K., and Atlam F. M. (2008) Quantum chemical studies on the inhibition of corrosion of copper surface by substituted uracils. Appl. Surf. Sci. 255 2433-2441. 
31. Markhali B. P., Naderi R., Mahdavian M., Sayebani M., and Arman S. Y. (2013) Electrochemical impedance spectroscopy and electrochemical noise measurements as tools to evaluate corrosion inhibition of azole compounds on stainless steel in acidic media. Corros. Sci. 75 269-279.

32. Meng Y., Ning W., Xu B., Yang W., Zhang K., Chen Y., Li L., Liu X., Zhenga J., and Zhangb Y. (2017) Inhibition of mild steel corrosion in hydrochloric acid using two novel pyridine Schiff base derivatives: a comparative study of experimental and theoretical results. $R S C A d v .7$ (68) 4301443029.

33. Dandia A., Gupta S. L., Quraishi M. A., and Singh P. (2013) Ultrasound assisted synthesis of Pyrazolo[3,4-b]pyridines as potential corrosion inhibitors for mild steel in $1.0 \mathrm{M} \mathrm{HCl}$, ACS Sustain Chem Eng. 1 (10) 1303-1310.

34. Deng S., Li X., and Fu H. (2011) Alizarin violet 3B as a novel corr osion inhibitor for steel in $\mathrm{HCl}$, $\mathrm{H}_{2} \mathrm{SO}_{4}$ solutions. Corros. Sci. 53 3596-3602.

35. Farag A. A., Migahed M. A., and Al-Sabagh A.M. (2015) Adsorption and inhibition behavior of a novel Schiff base on carbon steel corrosion in acid media. Egypt. J. Petrol. 24 (3) 307-315.

36. Daoud D., Douadi T., Issaadi S., and Chafaa S. (2014) Adsorption and corrosion inhibition of new synthesized thiophene Schiff base on mild steel X52 in $\mathrm{HCl}$ and $\mathrm{H}_{2} \mathrm{SO}_{4}$ solutions. Corros. Sci. 79 50-58.

37. Gupta N. K., Quraishi M.A., Verma C., and Mukherjee A. K. (2016) Green Schiff's bases as corrosion inhibitors for mild steel in $1 \mathrm{M} \mathrm{HCl}$ solution: Experimental and Theoretical approach. $R S C$ Adv. 6 (104) 102076-102087.

38. Jacob K. S., and Parameswaran G. (2010) Corrosion inhibition of mild steel in hydrochloric acid solution by Schiff base furoin thiosemicarbazone. Corros. Sci. 52 (1) 224-228.

39. Gupta N. K., Verma C., Quraishi M.A., and Mukherjee A.K. (2016) Schiff's bases derived from Llysine and aromatic aldehydes as green corrosion inhibitors for mild steel: Experimental and theoretical studies. J. Mol. Liq. 215 47-57.

40. Raphael V. P., Shaju K. S., and Thomas K. J. (2016) Monitoring the interaction of two heterocyclic compounds on carbon Steel by electrochemical polarization, noise, and quantum chemical studies. Int. J. Corros. 2016 1-10.

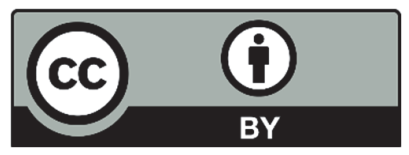

(C) 2021 by the authors; licensee Growing Science, Canada. This is an open access article distributed under the terms and conditions of the Creative Commons Attribution (CC-BY) license (http://creativecommons.org/licenses/by/4.0/). 